\title{
DNA barcoding of Schisandraceae in Korea
}

\author{
Jung Won Youm, Sang-Wook Han, Seon Won Seo, Chae Un Lim ${ }^{1}$ and Sang-Hun Oh* \\ Department of Biology, Daejeon University, Daejeon 34520, Korea \\ ${ }^{1}$ Plant Resources Division, National Institute of Biological Resources, Incheon 22689, Korea \\ (Received 20 August 2016; Revised 12 September 2016; Accepted 12 September 2016)
}

\section{한국산 오미자과의 DNA 바코드 \\ 염정원 · 한상욱 · 서선원 · 임채은 ${ }^{1}$ · 오상훈* \\ 대전대학교 생명과학과, ${ }^{1}$ 국립생물자원관 식물자원과}

\begin{abstract}
The establishment of a DNA barcode database at the regional scale and assessments of the utility of DNA barcodes are crucial for conservation biology and for the sustainable utilization of biological resources. Schisandraceae is a small family consisting of ca. 45 species. It contains many economically important species, such as Schisandra chinensis, which is widely used as a source in tonic beverages and in oriental medicine. In Korea, three species, S. chinensis, S. repanda, and Kadsura japonica, are distributed. We evaluated the level of variation of the DNA sequences of $r b c L$, matK, and the ITS regions from 13 accessions representing the distributional range of the three species. The three DNA barcode regions were easily amplified and sequenced. The minimum values of the interspecific genetic distances among $S$. chinensis, $S$. repanda, and $K$. japonica either separately or in combination are 4- to 23 -fold higher than the maximum value of the intraspecific distance, showing that there is a clear DNA barcoding gap in the regions for Korean Schisandraceae. Phylogenetic analyses of the three DNA barcode regions, separately and simultaneously, indicate that all of the DNA barcode regions are useful for identifying a species of Schisandraceae in Korea. The distinctiveness of the three species of Schisandraceae was also supported at the species level when Chinese and Japanese populations were added. The results of this study indicate that three concatenated regions constitute the best option for DNA barcoding in Schisandraceae in Korea.
\end{abstract}

Keywords: DNA barcoding, medicinal plants, Schisandraceae, species identification

DNA barcoding is a molecular technique which is used to identify a specimen with DNA sequences of short regions (Hebert et al., 2003; Kress et al., 2005; Xiang et al., 2011). With the advent of DNA sequencing methods and the lower cost of handling samples, the DNA barcoding method has proved to be a novel tool for the conservation of biodiversity at the global (Hebert et al., 2004; CBOL Plant Working Group, 2009) and the local levels (Lahaye et al., 2008; Tripathi et al., 2013; Kim et al., 2014; Zhang et al., 2015). With regard to plants, the $r b c L$ and $m a t K$ regions in the chloroplast genome are widely utilized by various groups (e.g., CBOL Plant Working Group, 2009). These DNA barcode regions are useful for identifying unknown specimens into families and genera, and sometimes to the species level (Lahaye et al., 2008). Additional DNA barcoding regions in chloroplast regions, such as trnH-psbA, atpF-atpH, and $p s b K-p s b I$, and Internal Transcribed Spacers (ITS) in nuclear ribosomal DNA have been suggested to augment the resolution power to lower taxonomic levels (Tripathi et al., 2013; Kim et al., 2014).

Because of its advantage for the identification of species

\footnotetext{
*Author for correspondence: soh42@dju.kr
} 
from a small fragment even without knowledge of the key morphological features and because a large number of samples can be processed in a short period of time, DNA barcoding has been particularly useful for non-specialists in plant taxonomy. Building a regional DNA barcode database for all known species is the first step in the making the DNA barcode method useful for diverse applications, such as trade control at the customs, conservation biology, the utilization of plant resources in bio-industries, and for forensic science. An evaluation of the utility of DNA barcode regions for each group of plants concerning the level of resolution of species given a set of DNA barcodes would provide a basic information for application (CBOL Plant Working Group, 2009).

Schisandraceae is a small family consisting of Schisandra Michx. with approximately 23 species and Kadsura Juss with ca. 22 species (Saunders, 1998, 2000). Plants of Schisandraceae are evergreen or deciduous woody vines with alternate and simple leaves and unisexual flowers with spirally arranged carpels or stamens. Members of this family are distributed in temperate and subtropical forests in eastern and Southeast Asia, except for S. glabra (Brickell) Rehder, which grows in the southeastern United States and central Mexico. In Korea, $S$. chinensis (Turcz.) Baill., S. repanda (Siebold \& Zucc.) Radlk., and $K$. japonica (L.) Dunal are distributed. While the latter two species are restricted to southern areas within Korea, $S$. chinensis is widely distributed. Schisandra chinensis is also cultivated for tonic beverages and oriental medicine (Panossian and Wikman, 2008; Jang et al., 2016).

Leaf and floral characters are important when classifying Schisandraceae (Saunders, 1998, 2000; Suh, 2007). When a specimen has a relatively complete morphology, each species is easily distinguished from one another. However, when only part of the plant is available for identification, it is difficult to classify a species with the morphological features. Furthermore, the three aforementioned species are distributed in neighboring countries. Schisandra chinensis is also distrubited in China, Russia, and Japan, and S. repanda and K. japonica also occur in Japan (Ohwi, 1965; Saunders, 1998, 2000). Lee et al. (2013) have developed species-specific RAPD (Random Amplified Polymorphic DNA) markers and SCAR (Sequence Characterized Amplified Region) markers for the Korean Schisandraceae and the Chinese S. sphenanthera Rehder \& E. H. Wilson. These molecular markers would be very useful to authenticate the specific species, in which unknown materials are one of the four species. DNA barcoding method would provide an additional molecular tool to identify a species, which does not require a prior knowledge about the species. The establishment of a regional DNA barcode database for the Korean population and an assessment of the utility of DNA barcoding for geographic structures are necessary to make the DNA barcoding tool useful (Kim et al., 2014). Recently, DNA barcoding loci were evaluated for Schisandraceae (Zhang et al., 2015), focusing on the development of DNA barcode markers for the Chinese populations of Schisandraceae but not on evaluating the level of molecular variation across the geographic ranges of widely distributed species.

The main objectives of the present study are (1) to develop a DNA barcode database for Korean Schisandraceae, (2) to assess the level of differentiation of the species, and (3) to evaluate the utility of DNA barcodes.

\section{Materials and Methods}

\section{Plant materials}

Thirteen samples of Schisandraceae in total were included in this study (Table 1). For the relatively common and widespread species of $S$. chinensis, seven plants were included to represent their distributional range. For $K$. japonica, restricted to the southern part of Korea, five plants were analyzed. Schisandra repanda is very rare, and one sample was included in this study. Voucher specimens were deposited at the Herbarium of the National Institute of Biological Resources (KB). We included Illicium anisatum L. as an outgroup in the phylogenetic analysis based on phylogenetic analyses (Hao et al., 2001; Liu et al., 2006; Zhang et al., 2015).

\section{DNA extraction, amplification, and sequencing}

Total DNA was extracted from fresh leaves or dried leaf materials with silica gel using the DNeasy Plant Mini Kit (QIAGEN, Hilden, Germany). Two DNA barcode regions of chloroplast DNA (cpDNA), the rbcL and matK regions, and one nuclear region (ITS) were amplified via polymerase chain reactions (PCR). Primers for the cpDNA barcodes were published in previous studies (Soltis et al., 1992; Sang et al., 1997; Cuénoud et al., 2002; Kress and Erickson, 2007) and are summarized in Kim et al. (2014). The ITS region was amplified using the primers its6 (5'-CCG CTT ATT GAT ATG CTT AAA CT-3') and its9 (5'-TCG TAA CAA GGT TTC CGT AGG TG-3'). The new primers for the ITS region, developed by the last author, have been shown to be useful to amplify difficult samples (Potter et al., 2007, Daniel et al., 2008). For each PCR reaction, $1 \mu \mathrm{L}$ of total DNA was included in a $20 \mu \mathrm{L}$ reaction mixture with Solg EF-Taq DNA polymerase (Solgent, Daejeon, Korea). Amplification of the target regions was conducted with a Veriti thermal cycler (Applied Biosystems, Carlsbad, CA, USA) under the following 
Table 1. Taxa and voucher information included in this study. GenBank accession numbers are listed in the following order: $r b c L, m a t K$, and ITS and WIGIS accession numbers are for $r b c L$ and $m a t K$. WIGIS is Wildlife Integrated Genetic Information System in National Institute of Biological Resources.

\begin{tabular}{|c|c|c|}
\hline Species & Voucher & GenBank \& WIGIS number \\
\hline \multirow[t]{7}{*}{ S. chinensis } & Gangwon-do, Inje-gun, 27 Sep 2013, Kim \& Kim 445702 (KB 445702) & $\begin{array}{l}\text { KX815952, KX815939, KX815926; } \\
\text { WBN0012118, WBN0012131 }\end{array}$ \\
\hline & $\begin{array}{l}\text { Gangwon-do, Jeongseon-gun, Mt. Hambaeksan, } 4 \text { Jun 2014, Nahm } 435129 \text { (KB } \\
\text { 435129) }\end{array}$ & $\begin{array}{l}\text { KX815951, KX815938, KX815925; } \\
\text { WBN0012117, WBN0012130 }\end{array}$ \\
\hline & $\begin{array}{l}\text { Chungcheongbuk-do, Yeongdong-gun, Mt. Minjujisan, } 19 \text { May 2012, Sun, Ahn \& } \\
\text { Hwang } 422406 \text { (KB 422406) }\end{array}$ & $\begin{array}{l}\text { KX815950, KX815937, KX815924; } \\
\text { WBN0012116, WBN0012129 }\end{array}$ \\
\hline & $\begin{array}{l}\text { Gyeongsangbuk-do, Ulju-gun, Mt. Goheonsan, } 3 \text { Jun 2010, Kim } 308588 \text { (KB } \\
\text { 308588) }\end{array}$ & $\begin{array}{l}\text { KX815949, KX815936, KX815923; } \\
\text { WBN0012114, WBN0012127 }\end{array}$ \\
\hline & $\begin{array}{l}\text { Gyeongsangbuk-do, Pohang-si, Mt. Naeyeonsan, } 12 \text { May 2010, Won, Kim \& Im } \\
281432 \text { (KB 281432) }\end{array}$ & $\begin{array}{l}\text { KX815948, KX815935, KX815922; } \\
\text { WBN0012113, WBN0012126 }\end{array}$ \\
\hline & $\begin{array}{l}\text { Gyeongsangnam-do, Geochang-gun, Mt. Gibaeksan, } 17 \text { May 2011, Hong } 469967 \\
\text { (KB 469967) }\end{array}$ & $\begin{array}{l}\text { KX815953, KX815940, KX815927; } \\
\text { WBN0012115, WBN0012128 }\end{array}$ \\
\hline & $\begin{array}{l}\text { Jeollabuk-do, Jangsu-gun, Mt. Namdeogyusan, } 6 \text { Aug 2009, Kim } 262351 \text { (KB } \\
\text { 262351) }\end{array}$ & $\begin{array}{l}\text { KX815947, KX815934, KX815921; } \\
\text { WBN0012112, WBN0012125 }\end{array}$ \\
\hline S. repanda & Jeju-do, Seogwipo-si, Eojeomiag-oreum, 13 Sep 2015, Oh 6796 (KB 563810) & $\begin{array}{l}\text { KX815954, KX815941, KX815928; } \\
\text { WBN0012119, WBN0012132 }\end{array}$ \\
\hline \multirow[t]{5}{*}{ K. japonica } & Jellanam-do, Sinan-gun, Heuksando Island, 9 Sep 2009, Ahn 367052 (KB 367052) & $\begin{array}{l}\text { KX815946, KX815933, KX815920; } \\
\text { WBN0012110, WBN0012123 }\end{array}$ \\
\hline & Jeju-do, Jeju-si, Hangyeong-myeon, 8 Aug 2010, Ahn 324618 (KB 324618) & $\begin{array}{l}\text { KX815944, KX815931, KX815918; } \\
\text { WBN0012111, WBN0012124 }\end{array}$ \\
\hline & $\begin{array}{l}\text { Jeju-do, Jeju-si, Chuja-myeon, Hachujado Island, } 26 \text { Aug 2009, Nahm \& Choi } \\
206618 \text { (KB 206618) }\end{array}$ & $\begin{array}{l}\text { KX815943, KX815930, KX815917; } \\
\text { WBN0012108, WBN0012121 }\end{array}$ \\
\hline & $\begin{array}{l}\text { Jeju-do, Jeju-si, Jocheon-eup, Dongbaekdongsan, } 26 \text { Jul 2009, Yu } 365101 \text { (KB } \\
365101 \text { ) }\end{array}$ & $\begin{array}{l}\text { KX815945, KX815932, KX815919; } \\
\text { WBN0012109, WBN0012122 }\end{array}$ \\
\hline & Jeju-do, Seogwipo-si, Donnaeko, 12 Oct 2008, So \& Kim 205923 (KB 205923) & $\begin{array}{l}\text { KX815942, KX815929, KX815916; } \\
\text { WBN0012107, WBN0012120 }\end{array}$ \\
\hline
\end{tabular}

conditions: initial denaturation at $95^{\circ} \mathrm{C}$ for $2 \mathrm{~min}, 35$ cycles of $95^{\circ} \mathrm{C}$ for $30 \mathrm{~s}, 55^{\circ} \mathrm{C}$ for $30 \mathrm{~s}$, and $72^{\circ} \mathrm{C}$ for $1 \mathrm{~min}$, followed by a final extension at $72^{\circ} \mathrm{C}$ for $5 \mathrm{~min}$. PCR products were examined on a $1 \%$ agarose gel in $1 \times$ TBE buffer, purified and were sent to Solgent for sequencing, which prepared the sequencing reaction using the same primers used in PCR with the BigDye Terminator v3.1 Cycle Sequencing Kit (Applied Biosystems). Sequences were determined using the 3730xl DNA analyzer (Applied Biosystems).

\section{Data analysis}

Sequences were edited in Sequencher version 5.0 (Gene Codes Corporation, Ann Arbor, MI, USA), aligned using MUSCLE (Edgar, 2004), and adjusted manually as needed. The sequence data generated in this study, designated as the Korean Schisandraceae data, were analyzed separately and in combination with previously published data which contains DNA barcode sequences from Chinese and Japanese samples
(Zhang et al., 2015). In their study, Zhang et al. (2015) included 14 species of Schisandra and six of Kadsura, including $S$. chinensis, S. repanda, and $K$. japonica. We obtained DNA sequences of $r b c L, m a t K$, and the ITS regions of all accessions of the three species published in Zhang et al. (2015) and analyzed these together with our data to examine whether the Korean accessions can be distinguished from the Chinese and Japanese accessions by the DNA barcodes. In addition, exemplar accessions of other species were included in a more inclusive analysis (Appendix 1). The expanded data included 36 accessions from 13 species of Schisandra and 13 from five of Kadsura. Phylogenetic analyses were conducted using the maximum parsimony (MP) and neighbor-joining methods (NJ) in PAUP* 4.0b10 (Swofford, 2002). All characters were treated as unordered and were weighted equally in the MP analyses. Gaps resulting from multiple alignments of indels were treated as missing. Heuristic searches were used with 100 replicates of random sequence additions with tree bisection-reconnection 
branch swapping, with all of the best trees saved at each step (MulTrees). Kimura's two-parameter model was employed to calculate the distance matrix in $\mathrm{NJ}$ analyses. Bootstrap analyses (Felsenstein, 1985) of 500 pseudoreplicates were conducted using both MP and NJ criteria. For the bootstrap analysis using the MP method, heuristic searches were employed with a simple sequence addition in PAUP* to evaluate the support for the Korean Schisandraceae data. For the expanded data matrix, 10,000 pseudoreplicates were sampled using the "fast" stepwise-addition option in PAUP*.

The resolution ability of the species for each DNA barcode and a combinatory DNA barcode were examined based on the percentage of monophyletic species given the MP and NJ trees. When only one accession in a species was included, it was treated as monophyletic if the branch leading to the accession was greater than zero.

\section{Results and Discussion}

The primers for the amplification and sequencing of the $r b c L$, $m a t K$, and ITS regions for the Korean Schisandraceae worked well, producing a success rate of $100 \%$. The lengths of the amplified $r b c L$ and matK regions were $646 \mathrm{bp}$ and $867 \mathrm{bp}$, respectively. The lengths of the ITS regions were $669 \mathrm{bp}$ in $S$. repanda, 670 bp in S. chinensis, and 672 bp in K. japonica. The size within a species was invariable in all three regions. The $r b c L$ sequences of all accessions of $S$. chinensis included were identical, as they were for $K$. japonica. In the matK data, five haplotypes were found, two in $S$. chinensis, two in $K$. japonica, and one in $S$. repanda. The ITS data produced intraspecific variation only in $S$. chinensis, in which four ribotypes were found among seven accessions. The final alignment of the concatenated data with Illicium anisatum as an outgroup resulted in 2,274 sites, of which 194 sites were variable and 44 were parsimoniously informative (Table 2).

$\mathrm{NJ}$ analyses of the three regions, separately and simultaneously, suggested that all three species were distinguishable by DNA barcodes (Fig. 1). MP analyses produced the same results as $\mathrm{NJ}$ analyses, except for the separate analysis from matK, in which relationship between $S$. chinensis and $S$. repanda was not resolved (Table 2). In all NJ and MP analyses, except for MP analysis of matK, multiple accessions of $S$. chinensis and $K$. japonica formed monophyletic groups with strong bootstrap values. Schisandra repanda, where only one accession was included, was divergent from S. chinensis and K. japonica and was not nested within either of the two species. Schisandra repanda was a sister to $S$. chinensis in the $r b c L$ and matK data with relatively high support values, resulting in mutually exclusive clades of Schisandra and Kadsura (Fig. 1A, B). Schisandra repanda, however, was resolved as a sister to $K$. japonica in the NJ analysis of the ITS data with a bootstrap value of $65 \%$ (Fig. 1C). The NJ tree is the only topology that groups $S$. repanda with $K$. japonica. The MP analysis of the ITS data suggested that $S$. repanda is a sister to $S$. chinensis. A combined analysis of the three regions showed that $S$. repanda is a sister to $S$. chinensis in both the NJ and MP methods. Our data indicate that all of the DNA barcode regions included in this study ( $r b c L, m a t K$, and ITS) are useful for identifying a species of Schisandraceae in Korea. The data also suggest that the resolution ability to distinguish all of the

Table 2. Statistics of DNA barcode regions for Schisandraceae in this study. Statistics for the combined Korean and other Asian species of Schisandraceae are shown in parentheses. Levels of species resolution power were calculated for three Korean species, including foreign populations of the species.

\begin{tabular}{lcccc}
\hline \hline & $r b c L$ & $m a t K$ & ITS & combined \\
\hline Number of sequences & $13(50)$ & $13(50)$ & $13(50)$ & $13(50)$ \\
Number of sites & $681(681)$ & $910(910)$ & $683(687)$ & $2,274(2,278)$ \\
Number of variable sites & $21(27)$ & $42(61)$ & $131(155)$ & $194(243)$ \\
Number of parsimony-informative sites & $9(15)$ & $10(29)$ & $25(62)$ & $44(106)$ \\
Number of MP trees & $1(19)$ & $2(1,976)$ & $3(3)$ & $4(4)$ \\
Tree length & $22(34)$ & $48(81)$ & $143(192)$ & $214(316)$ \\
CI, excluding autapomorphy & $0.9000(0.7619)$ & $0.8667(0.7083)$ & $0.8889(0.7980)$ & $0.8710(0.7288)$ \\
RI & $0.9744(0.9606)$ & $0.9512(0.9167)$ & $0.9630(0.9556)$ & $0.9574(0.9356)$ \\
Species resolution power, MP, NJ (\%) & $100,100(0.33,0.67)$ & $0.67,100(0,0)$ & $100,100(100,100)$ & $100,100(100,100)$ \\
Intraspecific distance (minimum-maximum) & $0.0-0.0$ & $0.0-0.0013$ & $0.0-0.0045$ & $0.0-0.0005$ \\
Interspecific distance (minimum-maximum) & $0.0045-0.0127$ & $0.0058-0.0160$ & $0.0254-0.0359$ & $0.0119-0.0192$ \\
\hline
\end{tabular}




\section{A. $r b c L$}

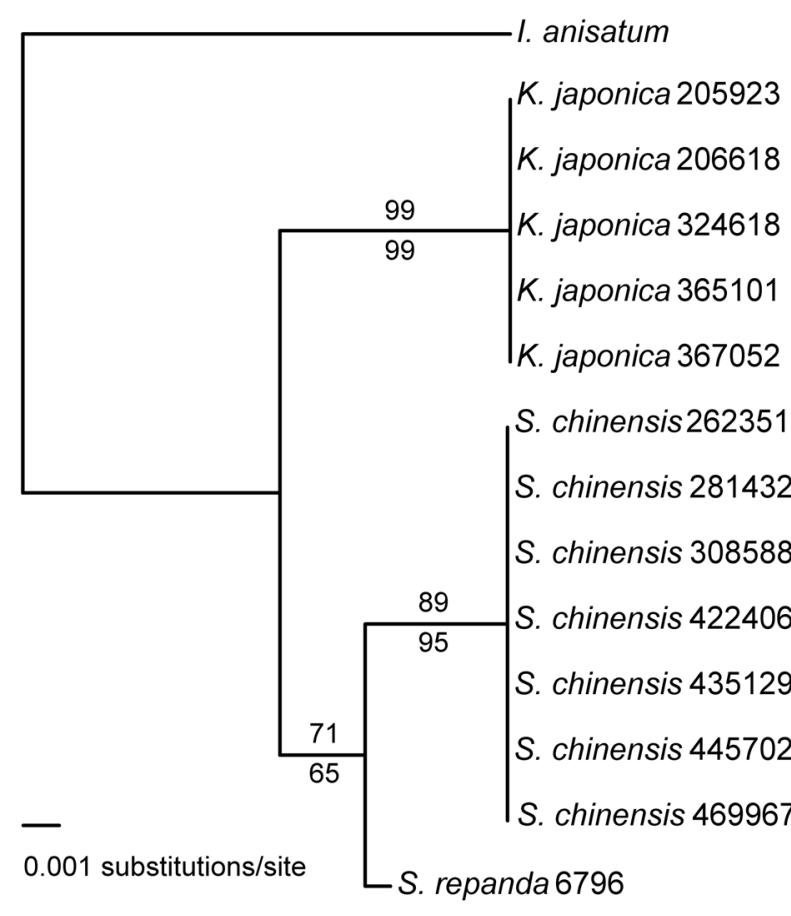

\section{ITS}

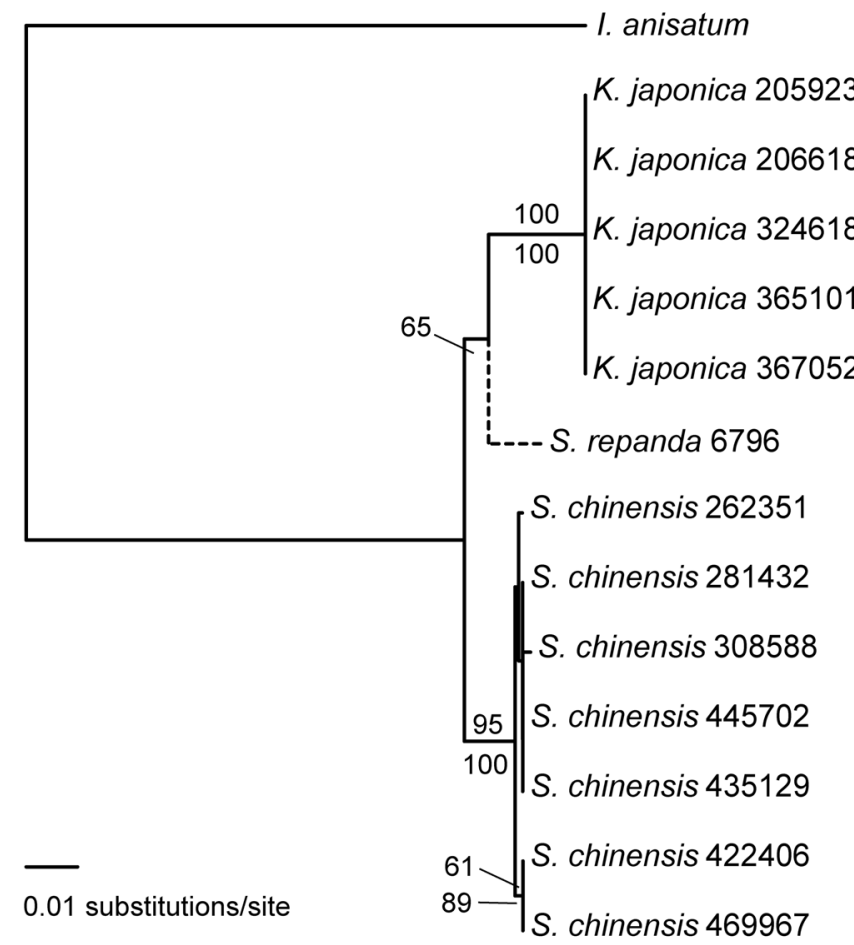

\section{B. matK}

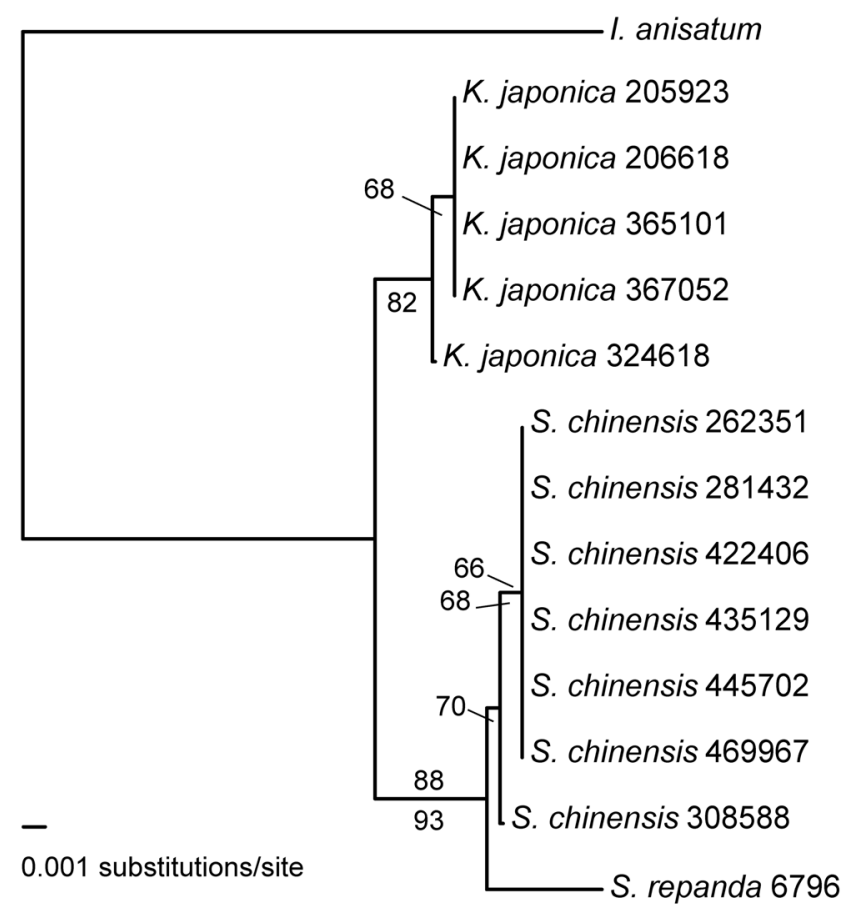

\section{D. combined}

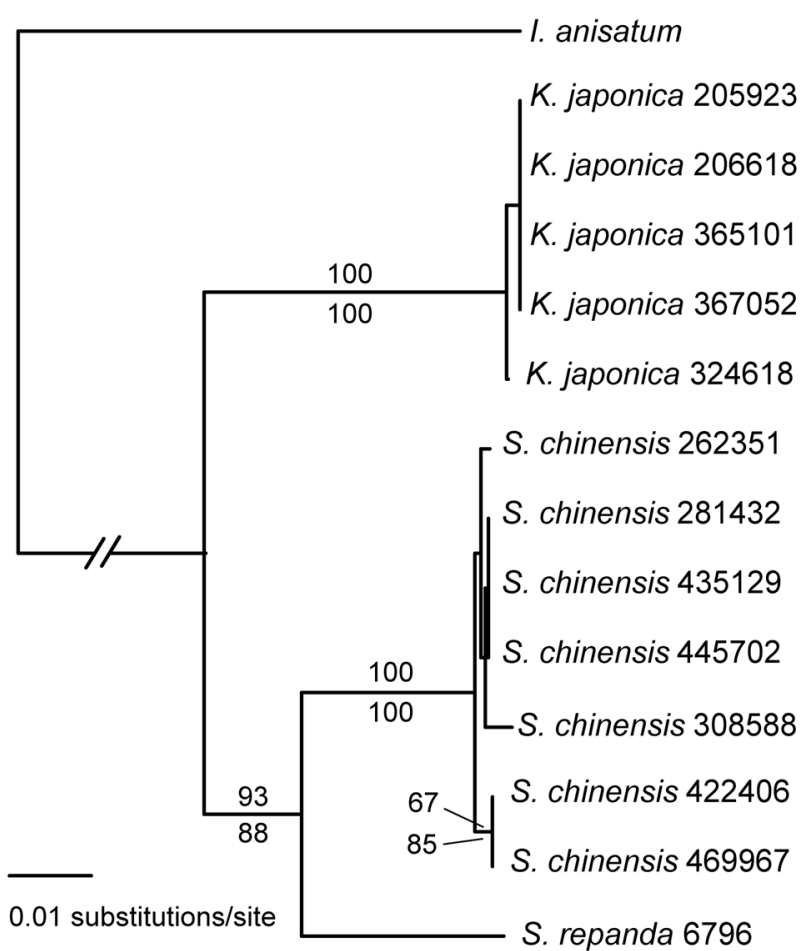

Fig. 1. Neighbor-joining trees from the analyses of the DNA barcode regions. A. $r b c L$. B. matK. C. ITS. D. combined data sets of the three regions. Numbers above and below branches indicate bootstrap values in the NJ and MP analyses, respectively. Schisandra repanda was a sister to $S$. chinensis in the MP analysis of the ITS region, as represented by the dotted line in $\mathbf{C}$. Numbers following the species name are DNA accession numbers to distinguish each individual. 
Korean species may be obtained by a single DNA barcode and a combinatorial barcode.

Our DNA barcode data are consistent with the morphology in that the three species of Schisandraceae in Korea are morphologically distinct (Saunders, 1998, 2000; Suh, 2007). Kadsura japonica is easily distinguished from $S$. chinensis and

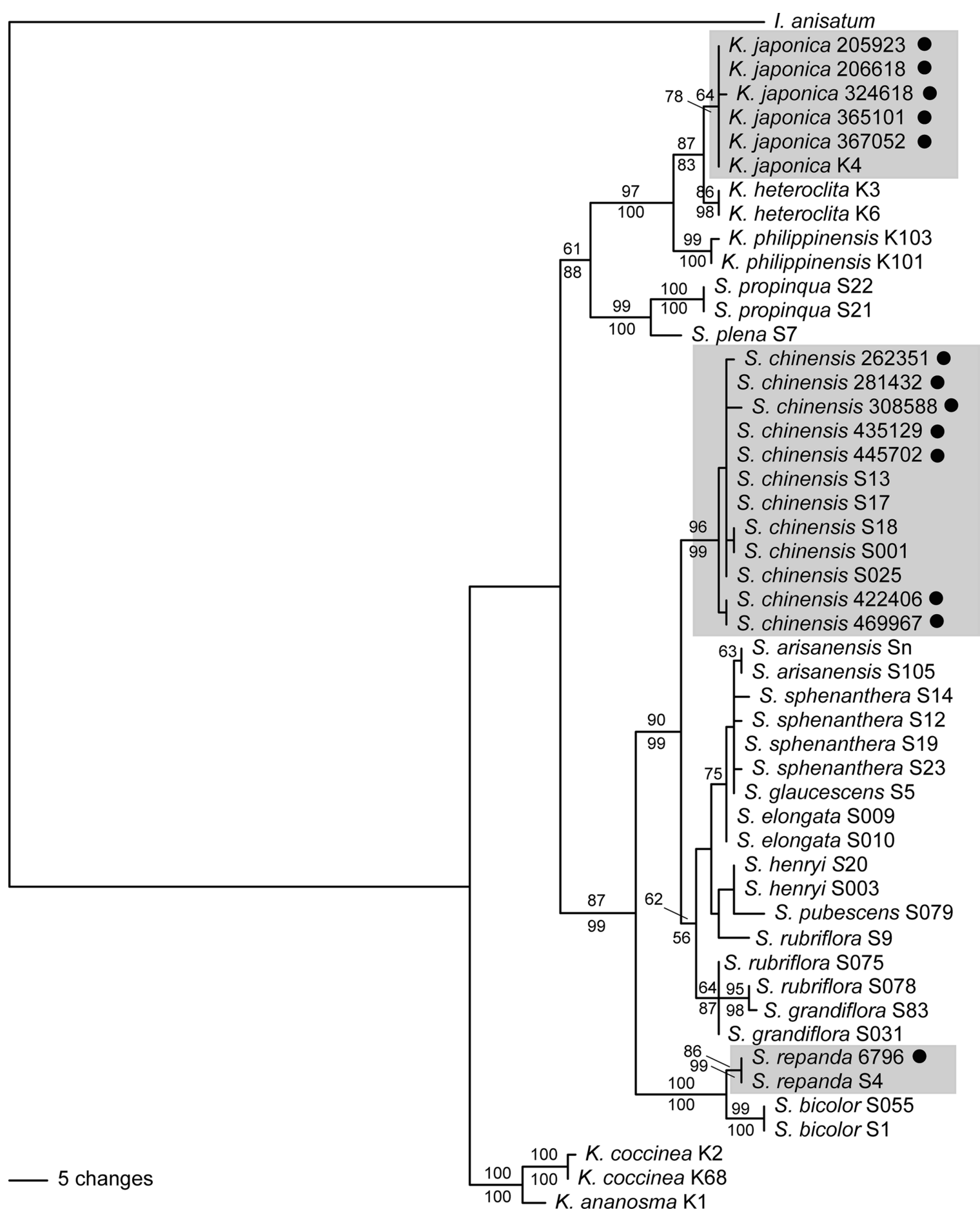

Fig. 2. One of four MP trees from the combined analysis of the $r b c L$, matK, and ITS regions from Schisandraceae. Samples collected in Korea for this study are indicated with closed circles. The three species distributed in Korea including foreign populations are marked with shaded boxes. Numbers above and below the branches indicate bootstrap values in the MP and NJ analyses, respectively. Numbers following the species name are DNA accession numbers to distinguish each individual. 
$S$. repanda by having globose aggregate of berries. Fruits of $S$. chinensis and S. repanda are aggregate berries that are loosely arranged along the axis, resembling the racemose infructescence, as the receptacle elongates when the fruit is mature. Plants of $K$. japonica are evergreen, while those of $S$. chinensis and $S$. repanda are deciduous. Schisandra repanda is rare in Korea, only distributed at high elevations on Mt. Hallasan in Jeju-do. This species can be distinguished from $S$. chinensis by having ovate or broadly elliptic leaves and black fruits. Stamens $S$. repanda are arranged at the margin of the flat pentagonal synandrous appendage, whereas those of $S$. chinensis are attached onto the columnar receptacle (Saunders, 2000; Liu et al., 2006).

Distinctiveness of the three species of Schisandraceae $(S$. chinensis, $S$. repanda, and $K$. japonica) was also supported at the species level when Chinese and Japanese populations were added to the combined data (Fig. 2). Kadsura japonica was a sister to $K$. heteroclita (Roxb.) Craib and S. repanda was a sister to S. bicolor W. C. Cheng. Schisandra chinensis is a sister to the clade of $S$. arisanensis Hayata and S. grandiflora Hook. f. \& Thompson (Fig. 2). Among the three regions, ITS regions provide the best resolution power in the expanded data (Table 2). In the $r b c L$ data, only S. chinensis was resolved as monophyletic in the MP analysis, while $S$. chinensis and $K$. japonica were resolved as monophyletic in the NJ analysis. The $m a t K$ data alone did not have sufficient power to resolve the three species in the expanded data (Table 2). Therefore, using three concatenated regions is the best option for DNA barcoding in Schisandraceae in Korea. The combined analyses of the expanded data showed that both Schisandra and Kadsura were not monophyletic (Fig. 2). Previous molecular phylogenetic studies of Schisandraceae also produced similar results (Hao et al., 2001; Liu et al., 2006; Zhang et al., 2015). Further detailed systematic studies are needed to investigate the generic boundaries of the two genera.

There is a clear gap between the distribution of the intraspecific distance and the distribution of the interspecific distance in all three species and in the combined data (Fig. 3). The minimum value of the interspecific distances among $S$. chinensis, $S$. repanda, and $K$. japonica in the DNA barcode regions either separately or in combination are 4 to 23 times higher than the maximum value of the intraspecific distance in the three species (Table 2). These results indicate that each species is genetically well differentiated and that all of DNA barcodes employed in this study should have power to distinguish a species.
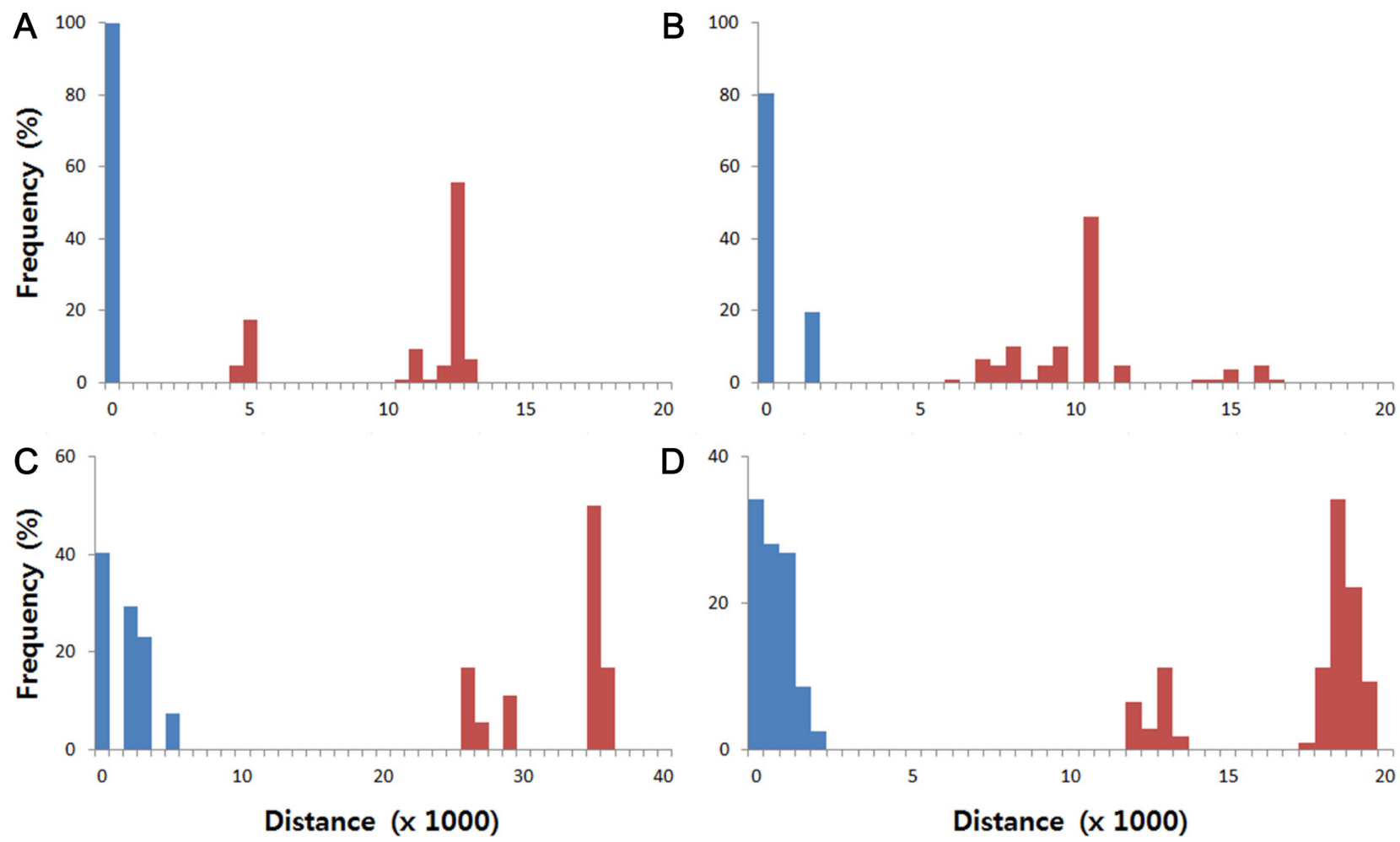

Fig. 3. Distribution of interspecific distance (red) and intraspecific distance (blue) calculated using Kimura's two-parameter model. A. $r b c L$. B. matK. C. ITS. D. Combined data sets of the three regions. 
Our data showed that the three DNA barcoding regions do not resolve the geographic origins of the samples in $S$. chinensis. Seven individuals of $S$. chinensis as sampled here were intended to represent the complete distributional range in Korea. The five Chinese samples used in Zhang et al. (2015) were collected in the Beijing and Jilin areas. We found four sequence types in Korea and two in China. Of these, one of the types in Korea with three populations (accession Nos. 281432, 435129, and 445702) was identical to a type in China with three individuals (accession Nos. S13, S17, and S025) in the combined data. The three Korean accessions were collected in montane areas of eastern Korea, such as Gangwon-do and Pohang-si (Table 1). The shared sequence type between Korea and China may represent a widely distributed type, as the sequence type was predominantly found in six out of twelve individuals. The other three sequence types derived from four individuals in Korea are unique, distinct from the second sequence type of China (accession Nos. S001 and S18). These Korean types may represent local types which are differentiated from common and ancestral types. However, S. chinensis is widely distributed in northeastern China, Mongolia, far eastern Russia, Korea, and Japan. Further studies are necessary to determine the geographic structure of the species with more samples of all distributional ranges and rapidly evolving molecular markers.

Schisandra repanda distributed in Korea and Japan was supported as a monophyletic group, a sister to S. bicolor (Fig. 2). This suggests that $S$. repanda is a well-supported species and that the DNA barcode regions have sufficient power to identify the species. Our study and that of Zhang et al. (2015) only sampled one individual of $S$. repanda. The sequences of the combined regions were identical in the two accessions, suggesting that the Korean population is undifferentiated from the Japanese one. These results also suggest that molecular marker for fine-scale analysis, such as microsatellite markers, should be employed to identify the geographic origins of samples in $S$. repanda.

Kadsura japonica is distributed in southern Korea and Japan (Honshu, Shikoku, Kyushu, and on the Ryukyu Islands) (Ohwi, 1965; Walker, 1976). Samples of $K$. japonica analyzed in this study were all from Korea, as was the sample used in Zhang et al. (2015). Our data indicate that the DNA barcode regions have sufficient resolution power to identify $K$. japonica. There are two sequence types within $K$. japonica. Accession No. 324618 from Jejudo Island differed from the remaining accessions by one base in the matK region. All other samples including those from Jejudo Island produced identical sequences. This suggests that the degree of genetic diversity in $K$. japonica in Korea is low.

\section{Acknowledgments}

The authors thank SeA Ryu, Wha Jung Suh, Jin-Dong Lee, EuiHo Eom, BongSeok Kim, SeongWon Lee, and YoungTae Yang for their help throughout this project. We are grateful to two anonymous reviewers for their critical reviews of the manuscript. This work was supported by a research grant, NIBR-201614101, from the National Institute of Biological Resources, Korea.

\section{Literature Cited}

CBOL Plant Working Group. 2009. A DNA barcode for land plants. Proceedings of the National Academy of Sciences of the United States of America 106: 12794-12797.

Cuénoud, P., V. Savolainen, L. W. Chatrou, M. Powell, R. J. Grayer and M. W. Chase. 2002. Molecular phylogenetics of Caryophyllales based on nuclear 18S rDNA and plastid $r b c L$, $a t p B$, and $m a t K$ DNA sequences. American Journal of Botany 89: $132-144$.

Daniel, T. F., L. A. McDade, M. Manktelow and C. A. Kiel. 2008. The "Tetramerium lineage" (Acanthaceae: Acanthoideae: Justicieae): Delimitation and intra-lineage relationships based on cp and nrITS sequence data. Systematic Botany 33: 416-436.

Edgar, R. C. 2004. MUSCLE: Multiple sequence alignment with high accuracy and high throughput. Nucleic Acids Research 32: 1792-1797.

Felsenstein, J. 1985. Confidence limits on phylogenies: An approach using the bootstrap. Evolution 39: 783-791.

Hao, G., M.-L. Chye and R. M. K. Saunders. 2001. A phylogenetic analysis of the Schisandraceae based on morphology and nuclear ribosomal ITS sequences. Botanical Journal of the Linnean Society 135: 401-411.

Hebert, P. D. N., A. Cywinska, S. L. Ball and J. R. deWaard. 2003. Biological identifications through DNA barcodes. Proceedings of the Royal Society B: Biological Sciences 270: 313321.

Hebert, P. D. N., E. H. Penton, J. M. Burns, D. H. Janzen and W. Hallwachs. 2004. Ten species in one: DNA barcoding reveals cryptic species in the neotropical skipper butterfly Astraptes fulgerator. Proceedings of the National Academy of Sciences of the United States of America, 101: 14812-14817.

Jang, M.-K., J. S. Nam, J. H. Kim, Y.-R. Yun, C. W. Han, B. J. Kim, H.-S. Jeong, K.-T. Ha and M. H. Jung. 2016. Schisandra chinensis extract ameliorates nonalcoholic fatty liver via 
inhibition of endoplasmic reticulum stress. Journal of Ethnopharmacology 185: 96-104.

Kim, H. M., S.-H. Oh, G, S. Bhandari, C.-S. Kim and C.-W. Park. 2014. DNA barcoding of Orchidaceae in Korea. Molecular Ecology Resources 14: 499-507.

Kress, W. J., K. J. Wurdack, E. A. Zimmer, L. A. Weigt and D. H. Janzen. 2005. Use of DNA barcodes to identify flowering plants. Proceedings of the National Academy of Sciences of the United States of America 102: 8369-8374.

Kress, W. J. and D. L. Erickson. 2007. A two-locus global DNA barcode for land plants: tThe coding $r b c L$ gene complements the non-coding trnH-psbA spacer region. PLoS ONE 2: e508.

Lahaye, R., M. van der Bank, D. Bogarin, J. Warner, F. Pupulin, G. Gigot, O. Maurin, S. Duthoit, T. G. Barraclough and V. Savolainen. 2008. DNA barcoding the floras of biodiversity hotspots. Proceedings of the National Academy of Sciences of the United States of America 105: 2923-2928.

Lee, Y. M., B. C. Moon, Y. Ji, H. S. Seo and H. K. Kim. 2013. Development of RAPD-derived SCAR markers and multiplex-PCR for authentication of the Schisandrae Fructus. Korean Journal of Medicinal Crop Science 21: 165-173. (in Korean)

Liu, Z., G. Hao, Y.-B. Luo, L. B. Thien, S. W. Rosso, A.-M. Lu and Z.-D. Chen. 2006. Phylogeny and androecial evolution in Schisandraceae, inferred from sequences of nuclear ribosomal DNA ITS and chloroplast DNA trnL-F regions. International Journal of Plant Sciences 167: 539-550.

Ohwi, J. 1965. Flora of Japan. Smithsonian Institution, Washington, DC, 1067 pp.

Panossian, A. and G. Wikman. 2008. Pharmacology of Schisandra chinensis Bail.: An overview of Russian research and uses in medicine. Journal of Ethnopharmacology 118: 183-212.

Potter, D., S. M. Still, T. Grebenc, D. Ballian, G. Božič, J. Franjiae and H. Kraigher. 2007. Phylogenetic relationships in tribe Spiraeeae (Rosaceae) inferred from nucleotide sequence data. Plant Systematics and Evolution 266: 105-118.
Sang, T., D. Crawford and T. Stuessy. 1997. Chloroplast DNA phylogeny, reticulate evolution, and biogeography of Paeonia (Paeoniaceae). American Journal of Botany 84: 1120-1136.

Saunders, R. M. K. 1998. Monograph of Kadsura (Schisandraceae). Systematic Botany Monographs. Vol. 54. American Society of Plant Taxonomists, Ann Arbor, MI, 106 pp.

Saunders, R. M. K. 2000. Monograph of Schisandra (Schisandraceae). Systematic Botany Monographs. Vol. 58. American Society of Plant Taxonomists, Ann Arbor, MI, 146 pp.

Soltis, P. S., D. E. Soltis and C. J. Smiley. 1992. An $r b c L$ sequence from a Miocene Taxodium (bald cypress). Proceedings of the National Academy of Sciences of the United States of America 89: 449-451.

Suh, Y. 2007. Schisandraceae Blume. In The Genera of Vascular Plants of Korea. Park, C.-W. (ed.), Academy Publishing Co., Seoul. Pp. 157-158.

Swofford, D. L. 2002. PAUP*: Phylogenetic analysis using parsimony (* and other methods), version 4.0. Sinauer Associates, Sunderland, MA.

Tripathi, A. M., A. Tyagi, A. Kumar, A. Singh, S. Singh, L. B. Chaudhary and S. Roy. 2013. The Internal Transcribed Spacer (ITS) region and trnH-psbA are suitable candidate loci for DNA barcoding of tropical tree species of India. PLoS ONE 8: e57934.

Walker, E. H. 1976. Flora of Okinawa and the Southern Ryukyu Islands. Smithsonian Institution Press, Washington, DC, 1159 pp.

Xiang, X.-G., H. Hu, W. Wang and X.-H. Jin. 2011. DNA barcoding of the recently evolved genus Holcoglossum (Orchidaceae: Aeridinae): A test of DNA barcode candidates. Molecular Ecology Resources 11: 1012-1021.

Zhang, J., M. Chen, X. Dong, R. Lin, J. Fan and Z. Chen. 2015. Evaluation of four commonly used DNA barcoding loci for Chinese medicinal plants of the family Schisandraceae. PLoS ONE 10: e0125574. 


\section{Appendix 1.}

List of samples downloaded from GenBank to include in the analysis with the Korean accessions of Schisandraceae. Accession numbers and locality information were obtained from Zhang et al. (2015). GenBank numbers were arranged in the following order: $r b c L, m a t K$, and Internal Transcribed Spacers (ITS).

Kadsura ananosma Kerr accession K1: China, Yunnan, Xishuangbanna, KP689928, KP689819, KP689710.

K. coccinea (Lemaire) A. C. Smith accession K2: China, Hunnan, Xinning, KP689923, KP689814, KP689705; accession K68: China, Sichuan, Emei, KP689925, KP689816, KP689707.

K. heteroclite (Roxb.) Craib accession K3: China, Hunnan, Xinning, KP689916, KP689807, KP689698; accession K6: China, Hunnan, Xinning, KP689915, KP689806, KP689697.

K. japonica (L.) Dunal accession K4: South Korea, Jellanam-do, Jindo, KP689922, KP689813, KP689704.

K. philippinensis Elmer accession K103: Taiwan, Nantou, KP689908, KP689799, KP689690; accession K101: Taiwan, Nantou, KP689910, KP689801, KP689692.

Schisandra arisanensis Hayata accession Sn: Taiwan, Taoynan, KP689856, KP689746, KP689638; accession S105: Taiwan, Nantou, KP689858, KP689748, KP689640.

S. bicolor W. C. Cheng accession S055: China, Hunnan, KP689899, KP689790, KP689681; accession S1: China, Hunnan, Xinning, KP689900, KP689791, KP689682.

S. chinensis (Turcz) Bail. accession S13: China, Beijing, KP689897, KP689788, KP689679; accession S17: China, Jilin, Tonghua, KP689894, KP689785, KP689676; accession S18: China, Beijing, KP689896, KP689787, KP689678; accession S001: China, Beijing, KP689895, KP689786, KP689677; accession S025: China, Jilin, Tonghua, KP689893, KP689784, KP689675.

S. elongate Hoof. f. \& Thompson accession S009: China, Chongqing, Yunyang, KP689867, KP689758, KP689650; accession S010: China, Chongqing, Wushan, KP689868, KP689759, KP689651.

S. glaucescens Diels accession S5: China, Chongqing, Nanchuan, KP689866, KP689757, KP689649.

S. grandiflora Hook. f. \& Thompson accession S83: China, Sichuan, Ebian, KP689887, KP68778, KP689669; accession S031: China, Xizang, Motou, KP689892, KP689783, KP689674.

S. henryi C. B. Clarke accession S020: China, Hubei, Yichang, KP689871, KP689762, KP689654; accession S003: China, Chongqing, Yunyang, KP689872, KP689763, KP689655.

S. pubescens Hemsl. \& E. H. Wilson accession S9: China, Chongqing, Nanchuan, KP689877, KP689768, KP689660.

S. repanda (Siebold \& Zucc.) A. C. Sm. accession S4: Japan, KP689898, KP689789, KP689680.

S. rubriflora Rehder \& E. H. Wilson accession S075: China, Yunnan, Kunming, KP689888, KP689779, KP689670; accession S078: China, Sichuan, Leibo, KP689883, KP689774, KP689665.

S. sphenanthera Rehder \& E. H. Wilson accession S14, China, Hunan, Hengyang, KP689863, KP689754, KP689646; accession S12, China, Shanxi, Ningshan, KP689861, KP689752, KP689644; accession S19, China, Hubei, Yichang, KP689865, KP689756, KP689648; accession S23, China, Henan, Nanyang, KP689862, KP689753, KP689645. 